\title{
Type IV Aggressive and Symptomatic Vertebral Hemangioma
}

\author{
Kawtar Nassar*, Wafae Rachidi, Saadia Janani, Ouafa Mkinsi \\ Rheumatology Department, Ibn Rochd University Hospital, Casablanca, Morocco \\ Email: "kawtarnassar@yahoo.fr
}

Received 30 July 2015; accepted 22 August 2015; published 25 August 2015

Copyright $@ 2015$ by authors and Scientific Research Publishing Inc.

This work is licensed under the Creative Commons Attribution International License (CC BY). http://creativecommons.org/licenses/by/4.0/

(c) (i) Open Access

\begin{abstract}
Vertebral hemangiomas (VHs) are benign tumours with rich vasculature. They are the most common tumours of the spine with an estimated incidence of $10 \%-12 \%$ of the population. Despite its high incidence, they are often asymptomatic and only $0.9 \%-1.2 \%$ are symptomatic. They may also be aggressive and are characterised by bone expansion, extra osseous extension of the tumour, disturbance of local blood flow and, in rare cases, compression fractures. We report a 59-year-old woman, presented with back pain after falling from standing height. Magnetic resonance imaging revealed lumbar spine vertebral fractures and T12 osteolytic lesion with spinal canal extension, concurring to VH type IV, according to Tomita's surgical classification of spinal. Embolization, posterior decompression and fixation were performed followed by postoperative radiotherapy. Her symptoms were resolved immediately without recurrence after 6 mouths.
\end{abstract}

\section{Keywords}

Vertebral Haemangioma, Extension, Radiotherapy, Ethanol Embolization, Surgery

\section{Introduction}

Vertebral haemangioma ( $\mathrm{VH}$ ) being called benign tumour is a vascular malformation, usually asymptomatic, but can on rare occasions cause pain and bone fractures [1]. The extraosseous soft-tissue component can extend into the epidural space causing compression of the spinal cord and nerve roots. Because of the rarity of aggressive $\mathrm{VH}$, diagnosis and treatment protocols for these cases remain controversial and problematic [2]. In this study, we report a 59-year-old woman case of T12 aggressive and symptomatic type IV VH with neurologic deficit, treated successfully until 6 months by Ethanol embolization, posterior decompression and fixation followed by postoperative radiotherapy. The evolution was in particular marked by the disappearance of pain.

${ }^{*}$ Corresponding author.

How to cite this paper: Nassar, K., Rachidi, W., Janani, S. and Mkinsi, O. (2015) Type IV Aggressive and Symptomatic Vertebral Hemangioma. Open Journal of Rheumatology and Autoimmune Diseases, 5, 87-91.

http://dx.doi.org/10.4236/ojra.2015.53014 


\section{Case Report}

The case is a 59-year-old woman without past medical history. She was presented with mechanical back pain after falling from standing height. Physical examination revealed weight at $61 \mathrm{~kg}$, height at $157 \mathrm{~cm}$. Loss of lumbar lordosis, thoracolumbar pain pressure, contractures of the paravertebral muscles, back pain caused by the mobilization of the spine. Low patellar reflexes, and muscle testing was at $4 / 5$ for relievers.

Plain radiographs of the thoracolumbar spine showed L1 and L2 benign vertebral fractures with grid appearance at T12 vertebra (Figure 1). MRI revealed T12 intensity signal on T1 and T2 with ductal extension, compatible with aggressive vertebral angioma (Figure 2 and Figure 3).

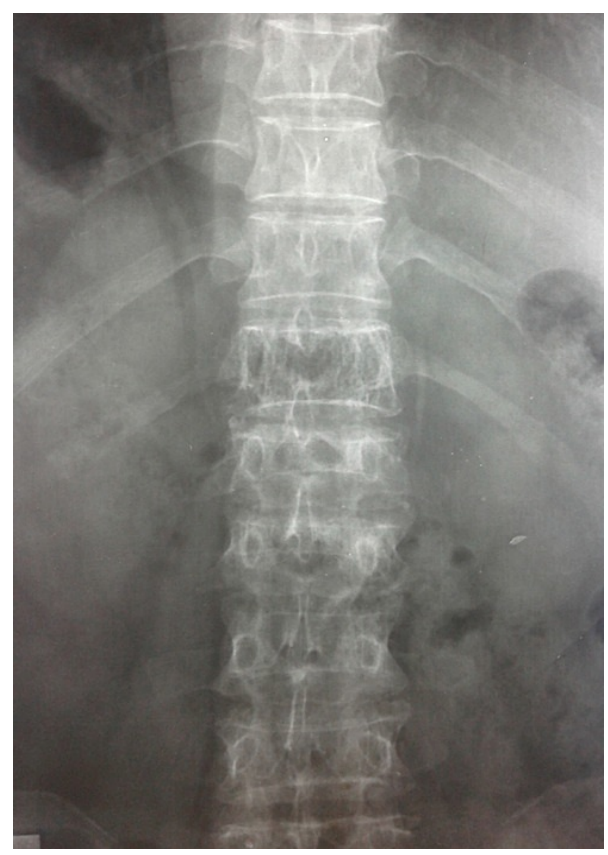

Figure 1. Plain thoraco-lumbar radiograph; L1 and $L 2$ vertebral fractures with grid appearance of the T12 vertebra.

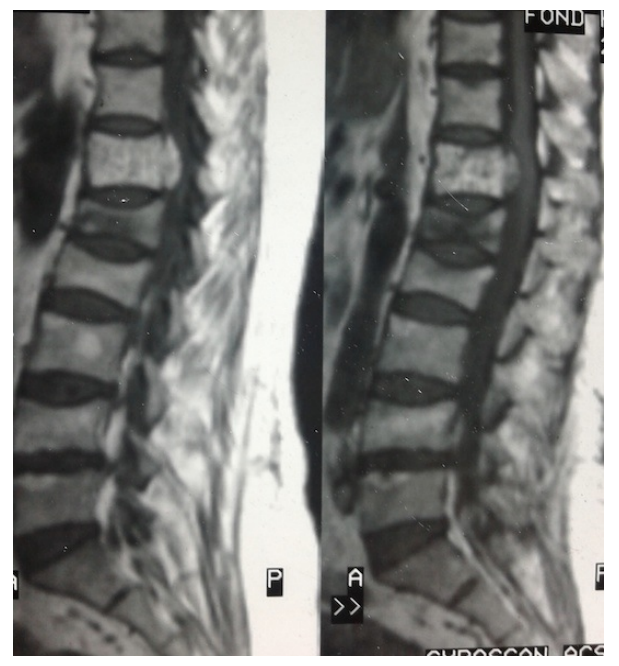

Figure 2. Sagittal thoraco-lumbar spine MRI showed intensity T12 signal T1 and T2, with spine canal extension and L1 benign vertebral fractures. 


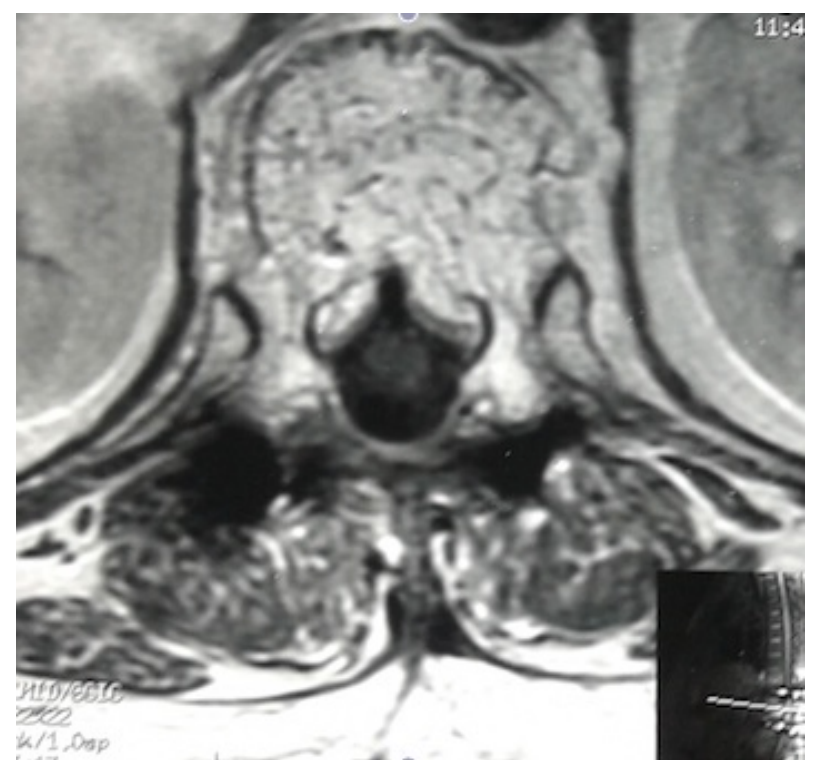

Figure 3. Axial MRI T12 image depicted that the lesion involved the vertebral body and spread into spinal canal.

At blood analysis, speed sedimentation was at $14 \mathrm{~mm} / 1$ hour, CRP at $2.7 \mathrm{mg} / \mathrm{l}$, normal electrophorese of protein, alcaline phosphate at $70 \mathrm{IU} / \mathrm{l}$, calcium and pshosphorus at $2.23 \mathrm{mmol} / \mathrm{l}$ and $1.19 \mathrm{mmol} / \mathrm{l} \mathrm{respectively.} \mathrm{Vita-}$ $\min \mathrm{D}$ at $8.90 \mathrm{ug} / \mathrm{l}$ then $31 \mathrm{ng} / \mathrm{ml}$, after correction. At osteodensitometry, we found -2.6 T-Score at lumbar spine, -2.3 at femoral neack and -1.8 in total femoral head. T-score was -3.5 at forearm. Parathormon value was at 45 pg.

Patient was treated successfully for 6 months by ethanol embolization, with posterior decompression (laminectomy and fixation), followed by radiotherapy sessions. After the 6 months of treatment, Thoraco-Lumbar MRI didn't found canal extension signal (Figure 4). Pain, neurological also disappeared and the clinical examination did not objectified signs for neurological deficit.

\section{Discussion}

Virchow first described VH in 1867, and Perman presented its first radiological description in 1926. Despite their common and usually benign occurrence, $11 \%$ of spines lesions at autopsy, vertebral hemangiomas can occasionally behave as aggressive tumours [3].

The diagnosis is usually made at middle and late middle age, frequently in the thoracic spine, followed by the lumbar spine. HVs are devided into four histologically categories: capillary, cavernous, arteriovenous or venour. Symptomatic VHs account for $0.9 \%-1.2 \%$ of cases, presenting with pain and neurologic compromise due to vertebral fracture and compression of nerve root or dual sac [4]. The tumour growth can produce compression, acute hemorrhage into the epidural space or spine cord ischemia because of hemodynamic effects [5].

Radiologically, they are characterised by the vertical striation and/or palisade pattern in the vertebral bodies. In addition, CT can demonstrate sparse vertebral trabeculae separated by fatty stroma. MRI examinations show high signals on both T1 and T2 images. The prognosis of VH lesions remains unclear. The presence of low signals on T1 weighted MRI and high signals on T2 images, the presence of soft tissue stroma between the osseous trabeculae on CT images, the presence of epidural tissue and evidence of cortical erosion are all radiological features of aggressiveness [6]. In our case, symptomatic lesion showed sign of aggressiveness on MRI examination.

There are three categories and seven types of VHs, according to Tomita's surgical classification of spinal tumours [7]: in the first category, the hemangioma is limited to vertebral body (type I), with pedicule extension (type II), body-lamina extension (type III). In the second category, VH is extra-compartmental: spinal canal extension (type IV), paravertebral (type V), and adjacent vertebral extension (type VI). In the third category, the VHs are multiple. 


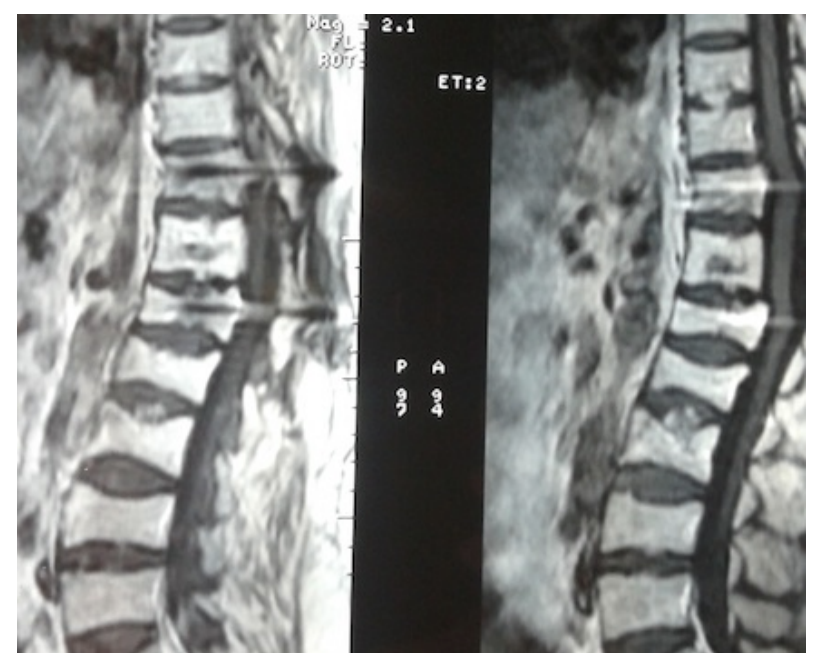

Figure 4. Sagittal thoraco-lumbar spine MRI image after surgery showed soft spine canal and vertebral body. Vertebral fractures and intra-spongy hernias of L1-L2.

The differential diagnosis includes infectious etiologies, metastatic lesions, primary malignancies of bone and soft tissue, abscess or osteomylitis [8]. However, the characteristics of radiographs findings and their chronicity significantly lowered the likehood of them.

Based on the patient's symptoms and lesions, VH can be classified into four categories [9], which treatment should be entirely depending:

I: Asymptomatic patients with no signs of aggressiveness; II: Symptomatic patients with no signs of aggressiveness; III: Asymptomatic patients with signs of aggressiveness; IV: Symptomatic patients with signs of aggressiveness.

Lei Dang and al. [10] suggested protocol for the diagnosis and management of aggressive vertebral hemangioma with neurological deficit, based on the literature and their previous experience.

The observation is needed for type I. For type II, the radiotherapy is effective with rare complications at 30 40 Gy over 3 - 4 week period, and vertebroplasty can cure VH by obstructing the vessels of tumour. Type III of VH can need observation, but spinal radiosurgery is a reasonable choice. Reported treatment protocol for type IV is more diversiform. It includes radiotherapy, vertebroplasty, direct alcohol injection, embolization arteries, surgery, and a combination of these modalities. Successful results have been reported for each of these modalities. Our patient presented satisfied results after combined embolization, surgery and radiotherapy.

\section{Conclusion}

Although vertebral hemangiomas are asymptomatic benign lesions with good outlook, there are symptomatic and aggressive cases with rapid onset of neuroligical deficits. The clinicians have to be aware of this condition as a differential and the place of MRI in order to expedite diagnosis. The symptomatic based treatment algorithm is well described. Clinicians and surgeons can coordinate to better elucidate the optimal management of these relatively rare lesions.

\section{Disclosure of Interest}

The authors declare that they have no conflicts of interest concerning this article.

\section{References}

[1] Cianfoni, A., Dani, G., Lena, J., Rumbold, Z., Vandergrif, W. and Bonaldi, G. (2014) Percutaneous Ethanol Embolization and Cement Augmentation of Aggressive Vertebral Hemangiomasat Two Adjacent Vertebral Levels. Journal of Neuroradiology, 41, 269-274. http://dx.doi.org/10.1016/j.neurad.2012.10.003

[2] Jiang, L., Liu, X.G., Yuan, H.S., Yang, S.M., Wei, F., Liu, C., Dang, L. and Liu, Z.J. (2014) Diagnosis and Treatment 
of Vertebral Hemangiomas with Neurologic Deficit: A Report of 29 Cases and Literature Review. The Spine Journal, 14, 944-954. http://dx.doi.org/10.1016/j.spinee.2013.07.450

[3] Liu, X.W., Jin, P., Wang, L.J., Li, M. and Sun, G. (2013) Vertebroplasty in the Treatment of Symptomatic Vertebral Haemangiomas without Neurological Deficit. European Radiology, 23, 2575-2581. http://dx.doi.org/10.1007/s00330-013-2843-9

[4] Kelekis, A., Dimitrios, K., Jean-Baptist, M. and Nikolaos, L. (2014) Aggressive Vertebral Hemangioma Treated with Combination of Vertebroplasty and Sclerotherapy through Transpedicular and Direct Approach. CardioVascular and Interventional Radiology, 37, 1638-1642. http://dx.doi.org/10.1007/s00270-013-0801-1

[5] Urrutia, J., Postigo, R., Larrondo, R. and San Martin, A. (2011) Clinical and Imaging Findings in Patients with Aggressive Spinal Hemangioma Requiring Surgical Treatment. Journal of Clinical Neuroscience, 18, 209-212. http://dx.doi.org/10.1016/j.jocn.2010.05.022

[6] Chen, H.I., Heuer, G.G., Zaghloul, K., Simon, S.L., Weigele, J.B. and Grady, M.S. (2007) Lumbar Vertebral Hemangioma Presenting with the Acute Onset of Neurological Symptoms. Journal of Neurosurgery: Spine, 7, 80-85. http://dx.doi.org/10.3171/SPI-07/07/080

[7] Tomita, K., Kawahara, N., Baba, H., Tsuchiya, H., Fujita, T. and Toribatake, Y. (1997) Total En Bloc Spondylectomy: A New Surgical Technique for Primary Malignant Vertebral Tumors. Spine, 22, 324-333. http://dx.doi.org/10.1097/00007632-199702010-00018

[8] Satoshi, K., Norio, K., Hideki, M., Satoru, D., Katsuhito, Y. and Tadaki, O. (2010) Surgical Management of Aggressive Vertebral Hemangiomas Causing Spinal Cord Compression: Long-Term Clinical Follow-Up of Five Cases. Journal of Orthopaedic Science, 15, 350-356. http://dx.doi.org/10.1007/s00776-010-1483-z

[9] Guarnieri, G., Ambrosanio, G., Vassallo, P., Pezzullo, M.G., Galasso, R., et al. (2009) Vertebroplasty as Treatment of Aggressive and Symptomatic Vertebral Hemangiomas: Up to 4 Years of Follow-Up. Neuroradiology, 51, 471-476. http://dx.doi.org/10.1007/s00234-009-0520-0

[10] Dang, L., Liu, C., Yang, S.M., Jiang, L., Liu, Z.J., Liu, X.G., Yuan, H.S., Wei, F. and Yu, M. (2012) Aggressive Vertebral Hemangioma of the Thoracic Spine without Typical Radiological Appearance. European Spine Journal, 21, 1994-1999. http://dx.doi.org/10.1007/s00586-012-2349-1 